\title{
Theoretical Analysis and Experimental Researches regarding the Asymmetrical Fluid Flow Applied in Aeronautics
}

\author{
Ionică Cîrciu, ${ }^{1}$ Doru Luculescu, ${ }^{1}$ Vasile Prisacariu, ${ }^{1}$ \\ Eduard Mihai, ${ }^{2}$ and Constantin Rotaru ${ }^{1}$ \\ ${ }^{1}$ Department of Aviation, "Henri Coandă" Air Force Academy, 160 Mihai Viteazul Street, 500183 Braşov, Romania \\ ${ }^{2}$ National Defence University "Carol I", Panduri Street No. 68-72, sector 5, 050662 Bucharest, Romania \\ Correspondence should be addressed to Ionică Cîrciu; circiuionica@yahoo.co.uk
}

Received 21 January 2015; Revised 27 March 2015; Accepted 30 March 2015

Academic Editor: Tang Xiaosheng

Copyright (C) 2015 Ionică Cîrciu et al. This is an open access article distributed under the Creative Commons Attribution License, which permits unrestricted use, distribution, and reproduction in any medium, provided the original work is properly cited.

The current paper has been written in order to find the best solutions to replace the antitorque rotor of single-rotor helicopters, with removal of its disadvantages through the Coandă Effect. This would significantly increase the flight performance. The research mainly aims at obtaining a controlled lateral force due to Coandă flows through the tail boom, a force which would be useful for the stabilization needed because of the lifting rotor during the flight of single-rotor helicopters.

\section{Introduction}

The Coandă effect is a classic phenomenon applied in fluid mechanics and one of the fundamental discoveries of the Romanian inventor Henri Coandă (1886-1972). He was a Romanian inventor, an aerodynamics pioneer, and the designer and builder of the world's first jet powered aircraft in 1910, a revolutionary plane of the beginning of the 20th century.

The lateral pressure that urges the flame of a candle towards the stream of air from a blowpipe is probably exactly similar to that pressure which eases the inflection of a current of air near an obstacle.

If you bring a convex body into contact with the side of the stream, the place of the dimple will immediately show that the current is deflected towards the body; and if the body was at liberty to move in every direction, it will be urged to move towards the current.

A hundred years later, Henri Coandă identified an application of the effect during experiments with his first aircraft which mounted an unusual engine designed by Coandă. The motor-driven turbine pushed hot air rearward, and Coandă noticed that the airflow was attracted to nearby surfaces.
He discussed this matter with leading aerodynamicist Theodore von Kármán who named it the Coandă effect. In 1934 Coandă obtained a patent in France for a "Method and apparatus for deviation of a fluid into another fluid." The effect was described as the "Deviation of a plain jet of a fluid that penetrates another fluid in the vicinity of a convex wall" $[1,2]$.

The Coandă effect is a natural phenomenon with action on the flow attached to a divergent wall (volet or airfoil) characterized by high asymmetry.

Figure 1 shows the main effect flow of a fluid characterized by the following aspects:

(a) The depressurized zone that determines a flow acceleration upstream in the slot, without increasing upstream pressure or temperature and the displacement of the local fluid.

(b) Detaching and reattaching are characterized by hysteresis (the reattaching is produced at smaller angles than the detaching).

(c) The global flow that results from the mixture between the main flow and the displaced one is situated in the depressurized zone and is characterized by lower temperature. 


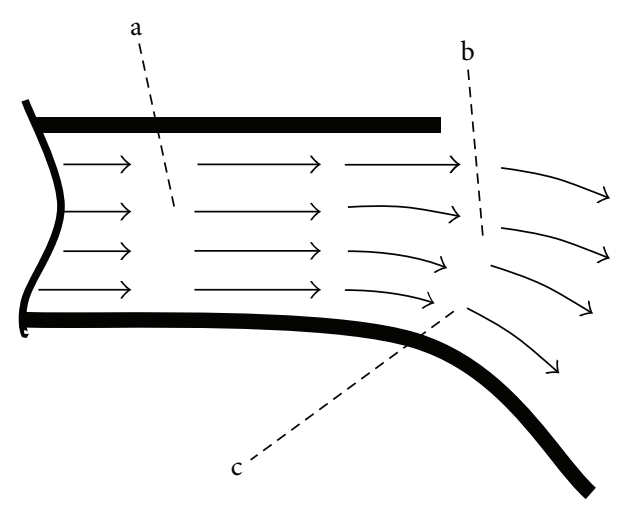

FIGURE 1: Coandă effect flow (2D).

\section{Theoretical Aspects of the Coandă Effect}

In Figure 2, the primary flow is introduced in the inlet (section $\mathrm{O}-\mathrm{O}$ ), by compression, or acceleration, or through absorption, directly from the environment.

The absorption section, marked with $(h-h)$, through which the inflow only advances, may be described as having the property that the total enthalpy $i^{*}$ of the inflow is equal with that of the environment, $i_{H}^{*}$. The place around $A$ is considered to be the longitudinal spot from the tail boom, where the loss of pressure of the flow is maximal. Section $B-B$ shows the end of the Coandă profile (line $O A B$ ). Section $C-C$ is the place where the absorption section ends and the mixing region extends to both walls. $D-D$ is the exit section from the air ejector and is characterized by the fact that the static pressure is equal with that of the environment static pressure $p_{H}$.

The area $h-O-C-B-h$ is considered to be the absorption area, where the total enthalpy, $i^{*}$, of the flow is $i^{*}=i_{H}^{*}$. Area $O-A B C-C-O$ is considered to be that of the junction where both flows mix, where the entire generated flow is received through the permeable surface $C-O$.

Area $C-D-D-C$ is the area of acquiring uniformity for the aero thermo gas dynamic parameters in section $C-C$ and it usually has a divergent form, which favourably contributes to the efficiency of the air ejector.

Its existence leads to the increase of the generated flow, but it does not necessarily mean an increase of the propulsion force $[3,4]$. The research on the force increase will have to take into consideration the entire geometry of the air ejector $[5,6]$. The known factors are

(i) geometry of the air ejector in its sections ( $A h, A O$, and $A D)$,

(ii) the slot conditions $\left(p^{*}, p_{0}\right)$,

(iii) environmental conditions $\left(p_{H}, \rho_{H}, i_{H}^{*}\right)$.

Also, for this global analysis of the mixture in the air ejector, the values of the energetic performance $\left(\eta_{C}, \eta_{D}\right)$ on sections $O O-C C$ and OO-DD are considered to be known.
Let's analyse a particular Coandă ejector with nonuniform and variable speed distribution, in exit section $D$. The static pressure $p_{D}$ equals the environment pressure $p_{H}$. The power transferred to the fluid in section $D$ is

$$
P_{0}=\eta P_{D}=\int_{A_{D}} \rho_{H} V_{D}(y)\left(i_{D}^{*}-i_{H}^{*}\right) d A_{D} .
$$

The gain in force is given by the difference between the two force distributions, with a maximal value corresponding to the angle.

We may describe a Coandă flow by using two zones, the centrifugal zone and the suction zone, each having special properties. The equations for the centrifugal zone, associated to the mixing region $O-A B C-C-O$ with the wall $C O$ considered to be permeable, are

$$
\begin{gathered}
\frac{1}{r} \cdot \frac{\partial\left(\rho \cdot u_{\omega}\right)}{\partial \omega}=0, \\
-\frac{u_{\omega}^{2}}{r}=-\frac{1}{\rho} \frac{\partial p}{\partial r} \\
u_{\omega} \frac{\partial u_{\omega}}{\partial \omega}=-\frac{1}{\rho} \frac{\partial p}{\partial \omega}, \\
i^{*}=i_{H}^{*}\left(\frac{p}{p_{H}}\right)^{(k-1) / k}+\frac{u_{\omega}^{2}}{2} .
\end{gathered}
$$

For a small element of the jet flow (Figure 3), the radial movement equation is

$$
\frac{d R}{R}=\frac{d p}{\rho u_{\omega}^{2}}
$$

For a point $\mathbf{B}_{\mathbf{i}}$ on the profile Coandă,

$$
u_{\omega}=u_{\omega_{0}} f_{u}(R) ; \quad u_{\omega_{0}}=u_{0} f_{u_{0}}
$$

and the total enthalpy is preserved:

$$
i^{*}(R)=\frac{\left[u_{\omega}(R)\right]^{2}}{2}+\left.\int \frac{\left[u_{\omega}(R)\right]^{2}}{R} d R\right|_{R}+i_{c}^{*} .
$$

The static pressure is expressed by

$$
p(R)=p_{H}\left(1+\left.\frac{1}{i_{H}^{*}} \int \frac{\left[u_{\omega}(R)\right]^{2}}{R} d R\right|_{R}\right)^{k /(k-1)}
$$

and the static parameters, as density and temperature, are

$$
\begin{aligned}
& \rho(R)=\rho_{H}\left(1+\left.\frac{1}{i_{H}^{*}} \int \frac{\left[u_{\omega}(R)\right]^{2}}{R} d R\right|_{R}\right)^{k /(k-1)}, \\
& T(R)=T_{H}\left(1+\left.\frac{1}{i_{H}^{*}} \int \frac{\left[u_{\omega}(R)\right]^{2}}{R} d R\right|_{R}\right)^{k /(k-1)} .
\end{aligned}
$$




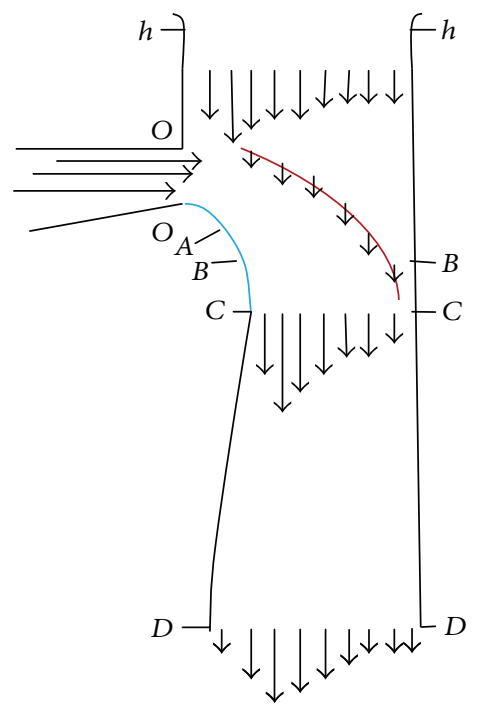

(a)

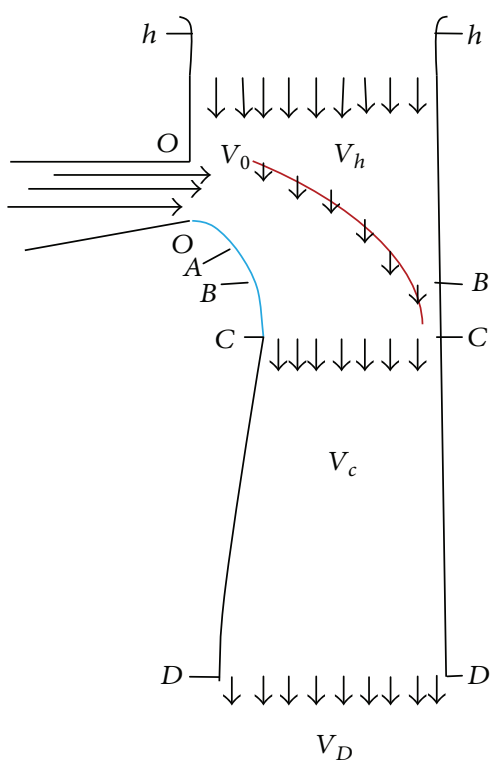

(b)

FIGURE 2: Coandă ejector with (a) nonuniform speed distribution and (b) uniform speed distribution.

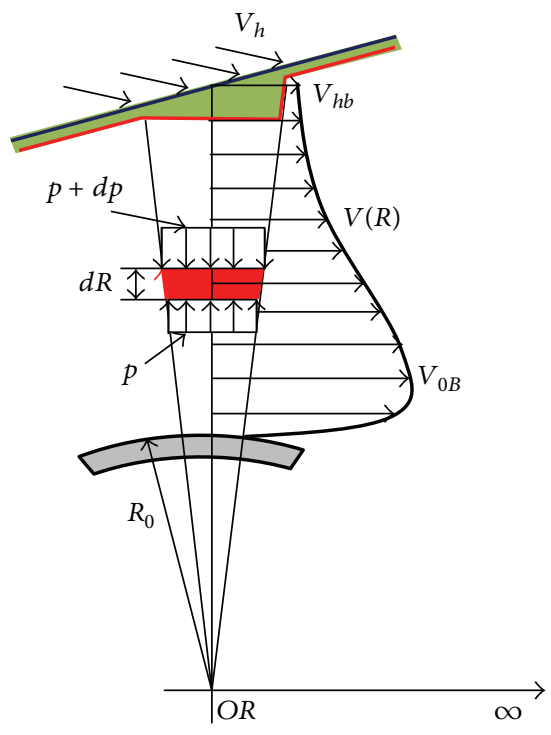

Figure 3: Jet flow elements.

The gain in force at $\mathbf{B}_{\mathbf{i}}$ is

$$
\begin{gathered}
\varphi_{\mathbf{B}_{\mathrm{i}}}=\frac{1}{b_{0}} \int_{R 1}^{R 2}\left(1+\left.\frac{1}{i_{H}^{*}} \int \frac{\left[u_{\omega}(R)\right]^{2}}{R} d R\right|_{R}\right)^{k /(k-1)} \\
\cdot f_{u_{0}}^{2} f_{u}^{2}(R) d R .
\end{gathered}
$$

We may note that the attached flow is situated in the depressurised zone (area defined by the slot exit frontier, $O$ $O, B-B$ section, and $D-D$ exit) having a maximal value in $A$ $[7,8]$. We assume that the section of the open slot $b_{0}$ has got the normal line perpendicular to the axis and due to

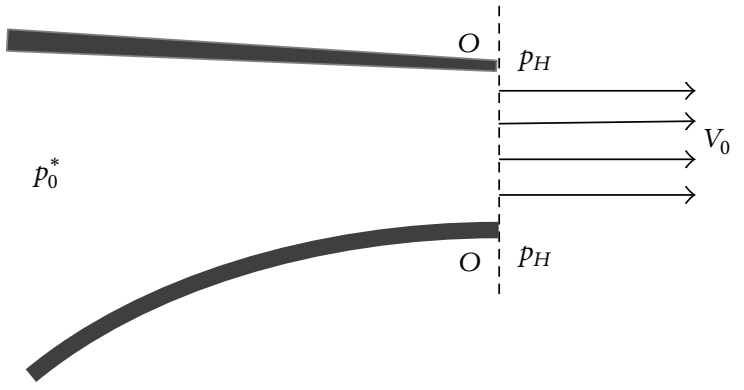

FIGURE 4: Free jet flow through the slot.

the Coandă profile (Figure 4) on one of its sides, there is some flow asymmetry revealed by asymmetrical distribution of the existing gas dynamic parameters within the section.

The speed $V_{0}$ of the expansion from $p_{0}^{*}$ at a pressure $p_{H}$ is

$$
V_{0}=\sqrt{2\left(i_{0}^{*}-i_{H}\right)}=\sqrt{2 i_{H}^{*}\left[\left(\frac{p_{0}^{*}}{p_{H}}\right)^{(k-1) / k}-1\right]} .
$$

Speed variation along the radius is assumed to be

$$
V(R)=V_{0}\left(\frac{R_{0}+b_{0}}{R}\right)^{n}
$$

and we have $V_{0}=V\left(R_{0}+b_{0}\right)$.

If the radius of curvature of the slot is big enough compared to the slot opening, we can approximate that the brake enthalpy is constant on the radius and the asymmetry is caused only by the static pressure variation from $p_{H}$ in the upper part of the slot to $p_{0}$ at the wall, in the lower part (Figure 5). 
TABLE 1

\begin{tabular}{lccccc}
\hline Nr.crt & Static pressure $\left[\mathrm{N} / \mathrm{m}^{2}\right]$ & $V_{c}[\mathrm{~m} / \mathrm{s}]$ & Force $F[\mathrm{~N}]$ & $F y[\mathrm{Nm}]$ & $F z[\mathrm{Nm}]$ \\
\hline 1 & 101237,4642 & 4,122222 & 2,26655 & 0,063376 & $-0,010004$ \\
2 & 101239,1528 & 4,178888 & 2,31825 & 0,068185 & $-0,012168$ \\
3 & 101240,7134 & 4,210001 & 2,40756 & 0,072684 & $-0,014505$ \\
4 & 101242,4722 & 4,290344 & 2,51815 & 0,076828 & $-0,01653$ \\
5 & 101244,1634 & 4,340777 & 2,62753 & 0,080975 & $-0,01827$ \\
6 & 101245,9927 & 4,386788 & 2,70147 & 0,085902 & $-0,018457$ \\
7 & 101248,1247 & 4,433453 & 2,74428 & 0,093680 & $-0,018168$ \\
8 & 101250,1457 & 4,532223 & 2,77195 & 0,102288 & $-0,017179$ \\
9 & 101252,0222 & 4,544555 & 2,80014 & 0,110612 & $-0,015722$ \\
10 & 101253,6918 & 4,666677 & 2,83484 & 0,116111 & $-0,013897$ \\
\hline
\end{tabular}

$V_{c}$ : the speed of the fluid through the tail boom.

$F$ : lateral force resulted from the Coandă effect.

$F y$ : torque on direction $y, F z$-torque on direction $z$.

TABLE 2

\begin{tabular}{|c|c|c|c|c|c|}
\hline Nr.crt & Static pressure $\left[\mathrm{N} / \mathrm{m}^{2}\right]$ & $V_{c}[\mathrm{~m} / \mathrm{s}]$ & Force $F[\mathrm{~N}]$ & $F y[\mathrm{Nm}]$ & $F z[\mathrm{Nm}]$ \\
\hline 1 & 101229,6367 & 4,122222 & 2,00683 & 0,03137 & $-0,00261$ \\
\hline 2 & 101229,7828 & 4,178888 & 2,02760 & 0,033470 & $-0,002413$ \\
\hline 3 & 101229,9896 & 4,210001 & 2,07610 & 0,035853 & $-0,000893$ \\
\hline 4 & 101230,0755 & 4,290344 & 2,10305 & 0,037589 & 0,000804 \\
\hline 5 & 101230,3241 & 4,340777 & 2,13139 & 0,039402 & 0,00094 \\
\hline 6 & 101230,7204 & 4,386788 & 2,15353 & 0,041249 & 0,00192 \\
\hline 7 & 101231,0777 & 4,433453 & 2,17919 & 0,042487 & 0,00277 \\
\hline 8 & 101231,4515 & 4,532223 & 2,21553 & 0,044657 & 0,00365 \\
\hline 9 & 101232,0023 & 4,544555 & 2,22803 & 0,046067 & 0,00538 \\
\hline
\end{tabular}

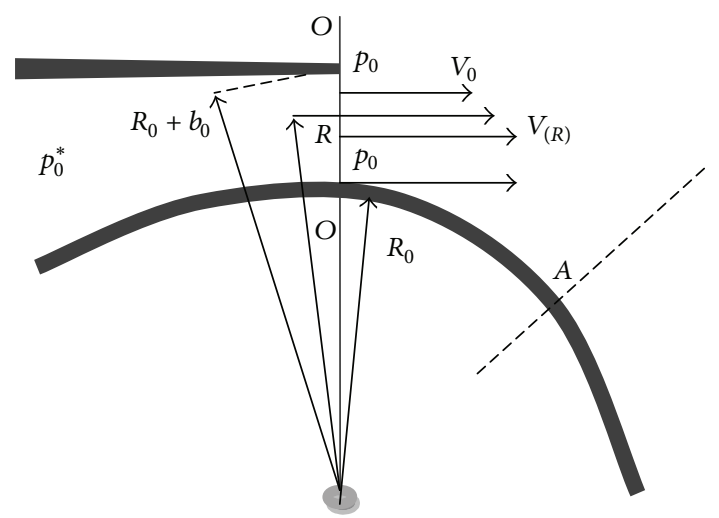

Figure 5: Coandă flow.

We write

$$
\begin{aligned}
p(R)=p_{H} & {\left[\frac{i_{0}^{*}}{i_{H}^{*}}-\frac{V_{(R)}^{2}}{2 i_{H}^{*}}\right]^{k /(k-1)} } \\
=p_{H} & \left\{\left(\frac{p_{0}^{*}}{p_{H}}\right)^{k /(k-1)}\right. \\
& \left.-\left[\left(\frac{p_{0}^{*}}{p_{H}}\right)^{k /(k-1)}-1\right]\left(\frac{R_{0}+b_{0}}{R}\right)^{2 n}\right\}^{k /(k-1)}
\end{aligned}
$$

which under limiting conditions gives

$$
p\left(R_{0}+b_{0}\right)=p_{H}, \quad p_{0}=p\left(R_{0}\right) .
$$

The outflow mass rate through the slot is

$$
\stackrel{*}{M_{0}}=\rho_{H} V_{0} A_{0} k_{M_{0}}
$$

where $k_{M_{0}}$ is the outflow increase coefficient; it is similar to the coefficient for the increase of the expansion area from $A_{0}$ to $k_{M_{0}} A_{0}$ having the constant speed $V_{0}$ or similar to the coefficient for the speed increase from $V_{0}$ to $k_{M_{0}} V_{0}$, having the same area as $A_{0}$ reference [9-11].

\section{Basic Modelling and Simulation Aspects regarding the Coandă Flow}

The interest is to compute the flow characteristics around some aerodynamic shapes with a particular focus on the tail (posterior fuselage) of IAR 316 B helicopter.

The results are presented in Figures 6 and 7.

The numerical simulations were made with Fluent 6.1 software program which allows modelling of the flows around a body.

Tables 1 and 2 show the values of the lateral force due to the Coandă effect at a vertical speed $V_{r}$ of the power lines of $15 \mathrm{~m} / \mathrm{s}$ and $V_{r}=10 \mathrm{~m} / \mathrm{s}$, respectively, depending on the variation of the speed of the flow within the tail boom. 


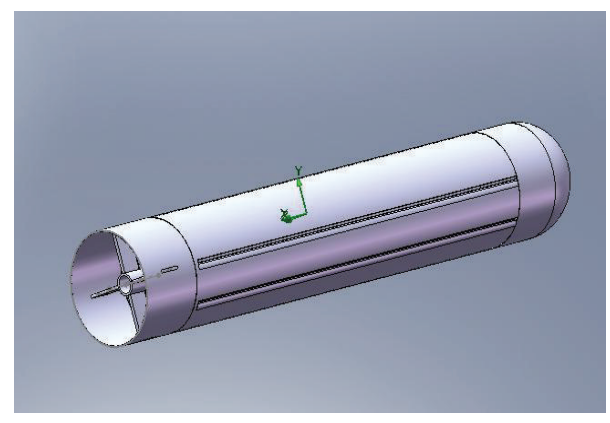

(a)

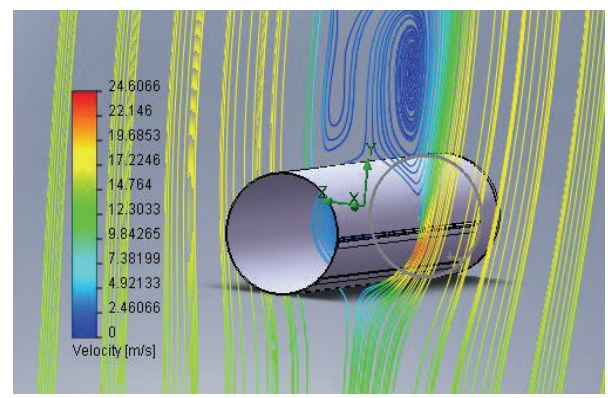

(b)

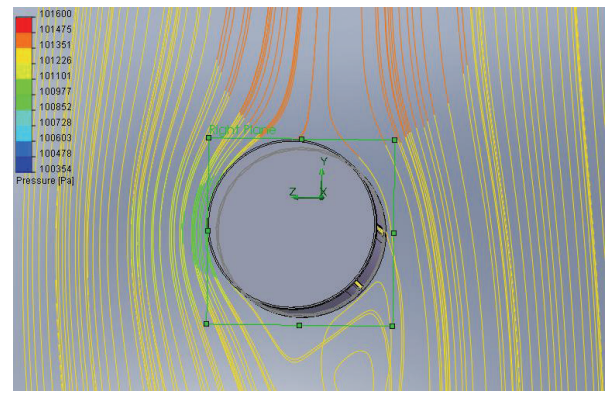

(c)

FIGURE 6: Simulation of the flow around the tail of IAR 316 B helicopter.

Ten values have been selected for interpretation and graphic presentation of force $F$ according to speed $V_{c}[6]$.

Table 1 shows the values of lateral force $F$ depending on the variation of the speed of the fluid through the tail boom $V_{c}$ by maintaining the vertical air current at a constant speed $V_{r}=15 \mathrm{~m} / \mathrm{s}$.

Table 2 shows the values of lateral force $F$ depending on the variation of the speed of the fluid through the tail boom $V_{C}$ by maintaining the vertical air current at a constant speed $V_{R}=10 \mathrm{~m} / \mathrm{s}$.

The diagram in Figure 8 shows the increase of lateral force $\mathbf{F}$ due to the Coandă effect and depending on speed $\mathbf{V}_{\mathbf{c}}$, through rounding the values to two decimal digits.

There is a linear increase of force $\mathbf{F}$, on small areas, compared to the mild increase of the speeds of the air stream through the tail boom, which makes us conclude that we can reach an increase of the lateral force $\mathbf{F}$ by mild variation of the rotation speed of the fan.

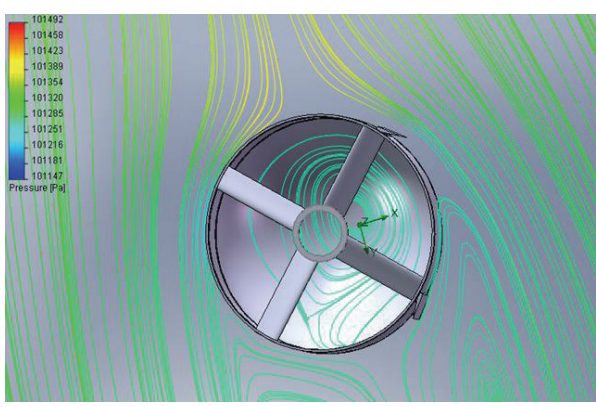

(a)

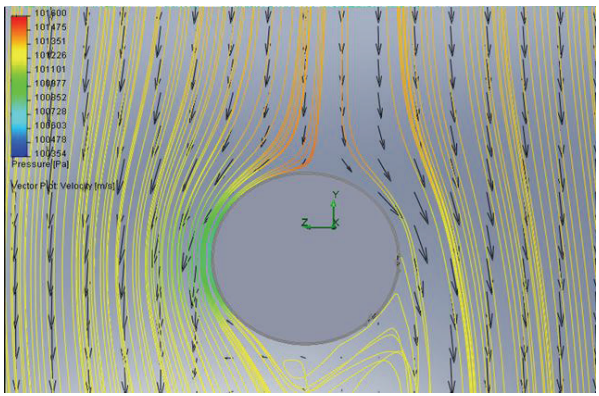

(b)

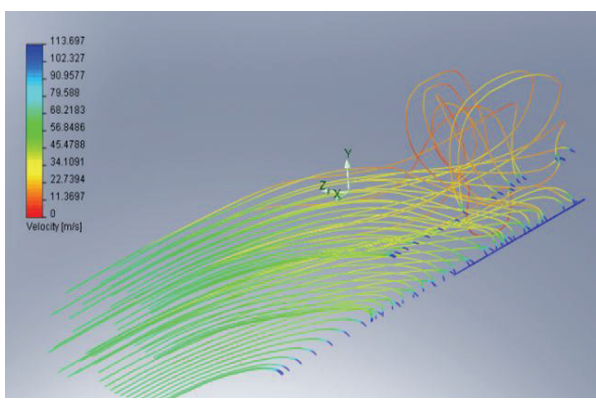

(c)

Figure 7: A complete 3D view of the flow.

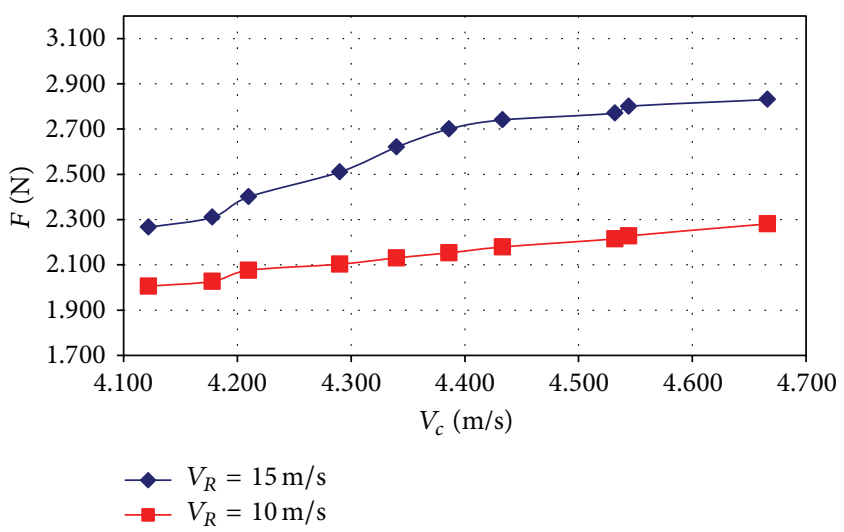

FIgURE 8: A comparative analysis of the variation of the lateral force for a constant $V_{R}$ of $15 \mathrm{~m} / \mathrm{s}$ and $10 \mathrm{~m} / \mathrm{s}$, respectively. 

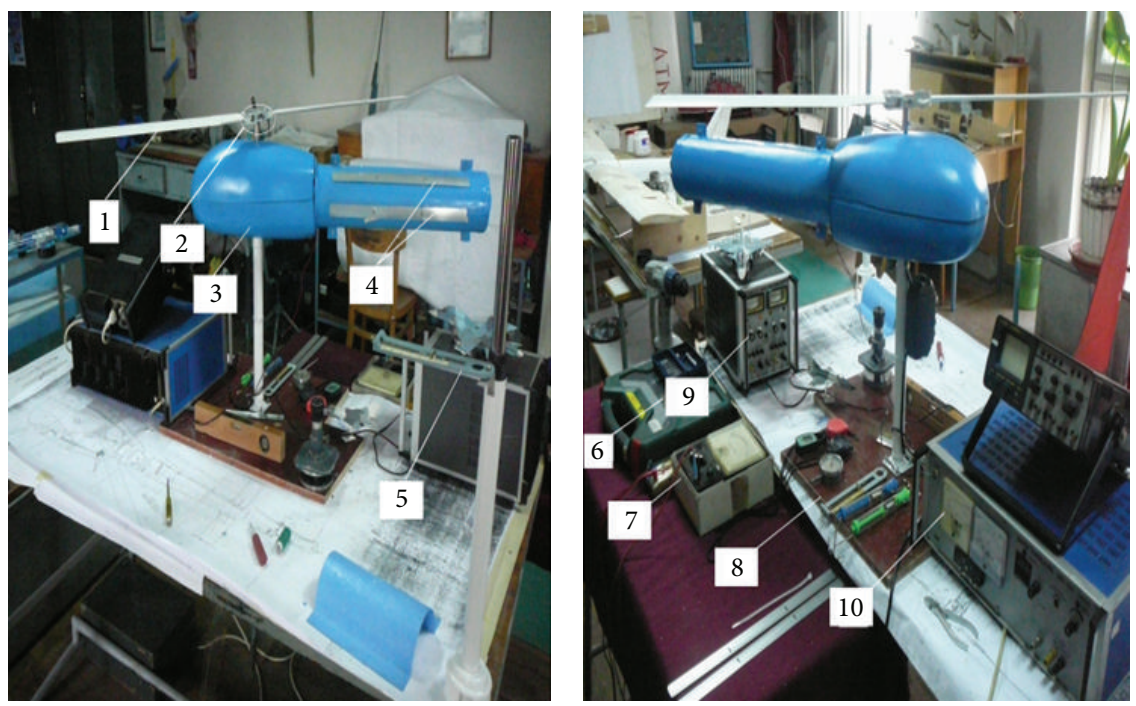

FIgURE 9: Experimental device: 1: NOTAR helicopter blades carbon fiber, 2: hub pitch, 3: structure helicopter fiberglass, 4: Coandă slots, 5: device measuring dynamometer force $F, 6$ : tool kit with, 7: measuring and control equipment, 8: instruments for making measurements (timer, dynamometers, Anemometers electronic, mechanical comparator, and roulette), 9: dual source DC power, and 10: stabilized power source and electronic oscilloscope.

\section{Experimental Research on the Application of Coandă Effect}

The correct results regarding the Coandă effect on the tail boom are reached by connecting the theoretical and computational studies as well as by putting into practice the profiles that need constant adjustments and they relate to

(i) the variation of the airflow generated by the main rotor (there are two variables here: the pitch angle and the rotation speed of the blades),

(ii) the variation of the air jet induced in the tail boom through the variable pitch fan,

(iii) the geometry of the profile (in our case being the tail boom),

(iv) the number of Coandă slots and their geometry (including width $\delta$ and length $l$ ).

It is to be noticed that appropriate, realistic results concerning the fluid flow under the Coandă effect have been reached through practical experiments by means of hundreds of convenient adjustments and changes of the variables.

The experimental device, as observed in the working principle schema and the physical schema in Figure 9, consists of I.A.R.316B helicopter model, at a scale of $1: 10$, provided with the entrainment elements, namely, the measuring and control equipment. The experimental device (Figure 9) aims at gaining a lateral force $F$ as strong as possible. The fluid flows along the tail boom and along the desired distance as well as the variation of the lateral force $F$ due to the Coandă effect having been analyzed. This was an attempt to create an adjustable, optimum Coandă profile depending on the flows generated by the main rotor, the tail fan, and the slot geometry and position. This optimization gives the possibility to replace the antitorque rotor, removing its disadvantages, and creates the advantage of big (maximum) lateral forces with low-energy consumption, which are found in helicopter performance calculations. In order to obtain the biggest lateral force possible, the application of slots on the tail boom was enlarged. This implies the modification of the force of the arm and the calculation of the application of the two slots in such a manner that the addition of the first air jet from the first slot turns into a fluid entrainment mass for the second slot. This entrainment of the fluid increases the surface of the Coandă profile. Thus, the entrainment of the fluid through the two slots generates a Coandă flow and the air mass that "attaches" itself to the fuselage (tail boom surface) becomes, in its turn, an adjustable surface of a new Coandă profile through the vertical flow induced by the main rotor [6]. This implies the modification of the force of the arm and the calculation of the application of the two slots in such a manner that the addition of the first air jet from the first slot turns into a fluid entrainment mass for the second slot. Because of the use of new composite materials, particularly carbon fiber, there is possibility to increase the beam of the geometric elements of the queue, namely, the length and large diameter, thin-walled tube, and the complete construction (Figures 9 and 10).

The occurrence of any reinforcements placed inside the inner flow leads to lower system efficiency. Carbon fibresreinforced composite laminate based on Huntsman XB3585 epoxy resin presents excellent mechanical properties especially along fibres direction. These properties are used as replacement in the automotive and aeronautics industry [5].

Varied elements and measurements:

(i) the relief angle $\theta$ (formed by the null bearing axis and the rotation plane) or the blade pitch $p$,

(ii) the rotation speed $V_{R}$ of the main rotor, 


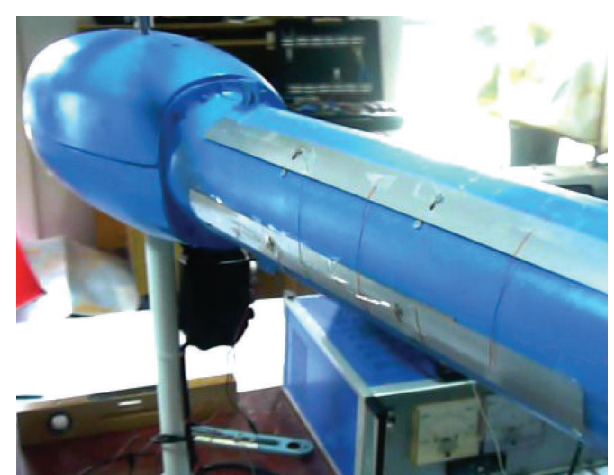

FIGURE 10: A helicopter structure consists of two main components: a cabin and tail beams of composite materials.

(iii) the rotation speed $V_{c}$ of the intubated fan from the tail boom,

(iv) the entrainment power $P$ of the main rotor,

(v) the entrainment power $P_{c}$ of the intubated fan from the tail boom.

Calculated measurements and reference points:

(i) length of movement in time sequences (reaction to controls),

(ii) speed and flow of the air jet moving through the tail boom,

(iii) speed and flow of the air flux generated by the main rotor,

(iv) speed of the fluid mixture around the slots.

Adjustment of the pitch is achieved through rotating blade grips on the hub, measuring the angle, and blocking them using a limiting screw. Angles are established with the help of a protractor and a pitch adjuster.

The rotation speed of the main rotor is achieved through three stages by manipulating the centre taps of the alternating current mains transformer as follows: $100 \mathrm{rot} / \mathrm{min}$; $144 \mathrm{rot} / \mathrm{min}$; and $198 \mathrm{rot} / \mathrm{min}$.

The rotation speed of the fan is achieved slowly as the fan is controlled through voltage, therefore by modifying the power-supply voltage of direct current.

The opening of the slots and of the angle of inclination is reached with the help of the adjustable limiting screw.

Since their values were small, measurements of the Coandă forces due to the air jet generated by the tail boom fan were interpreted with the help of a UMF 1/100. Variation of the power applied on the tail boom fan is reached with the help of the adjustable direct current supply IEMI I 4102 $\mathrm{M} 2 \mathrm{X} 40 \mathrm{~V} 1,2 \mathrm{~A}$ while the interpretation of the voltage and current is according to the measurement scheme containing the electronic multimeters. The phenomenon is highlighted by means of following the fine silk thread curves, which is measurable with the help of the dynamometers and the electronic anemometer.

Figures 11 and 12 show the modification of the lateral force due to the Coandă effect depending on the modification of

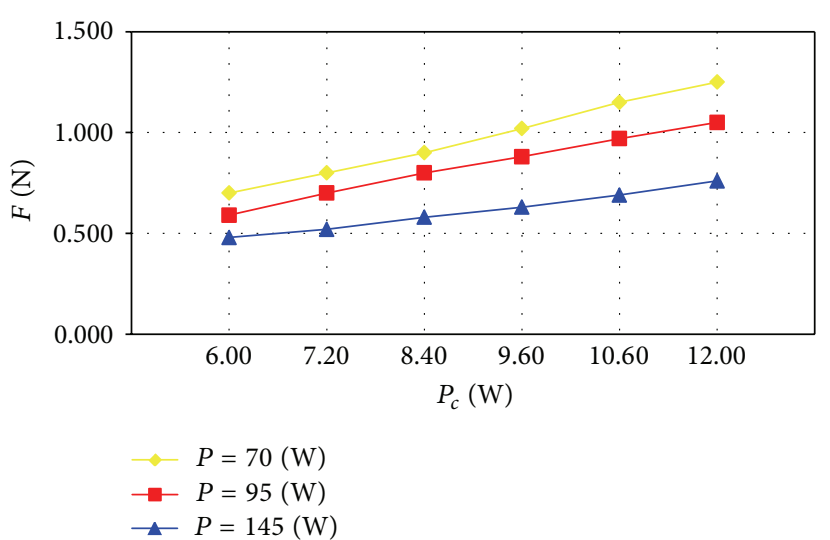

FIGURE 11: Lateral force variation due to the Coandă effect at constant values $p=4^{\circ}$ and $\delta=2 \mathrm{~mm}$.

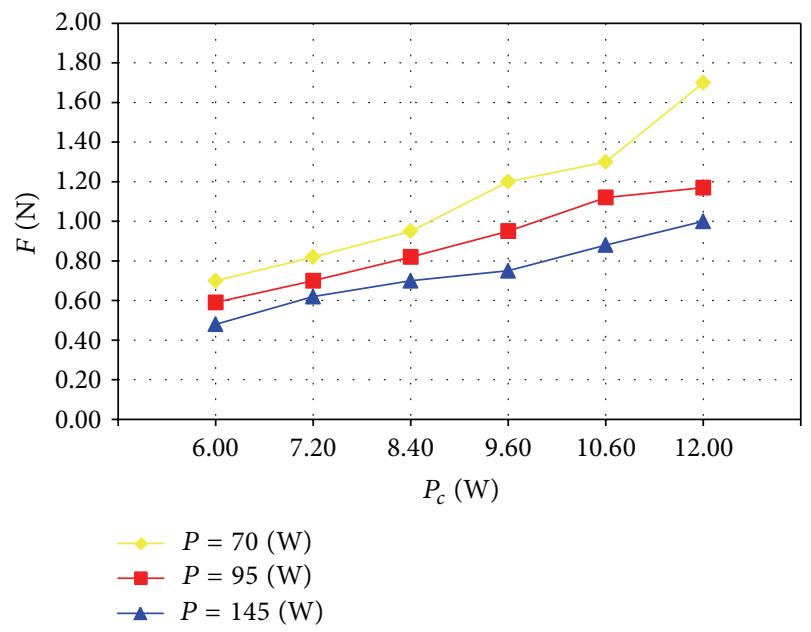

FIGURE 12: Lateral force variation due to the Coandă effect at constant values $p=8^{\circ}$ and $\delta=2 \mathrm{~mm}$.

the useful power (three values: $\mathbf{P}=70[\mathrm{~W}] ; 95[\mathrm{~W}] ; 145[\mathrm{~W}]$ ) applied to the main rotor, while maintaining the constant width $\delta=2 \mathrm{~mm}$ of the slots in accordance with the same values of the pitch angle of the blades $4^{\circ}$ and $8^{\circ}$.

For each value of the useful power applied to the main rotor, six power stages $P_{c}$ for the tail boom fan were used.

An approximately linear increase of the lateral force $F$ for each value of power $P$ can be noticed, thus facilitating the estimation of a family of linear functions $g_{N}$ which can be used to determine the relation force-applied powers.

For $P=95[\mathrm{~W}]$ with constant pitch angle $p=4^{0}$ and $\delta=2 \mathrm{~mm}$, get the results shown in Figure 12 .

We obtain a linear function $g_{N}$ which can be used to find the value of the lateral force $F$ generated by the Coandă effect:

$$
g_{N} \approx \frac{1}{100}(8 X+9) \text {. }
$$

If the pitch angle $p=8^{0}$ changed, the measured values were interpreted graphically, the results obtained being likely 


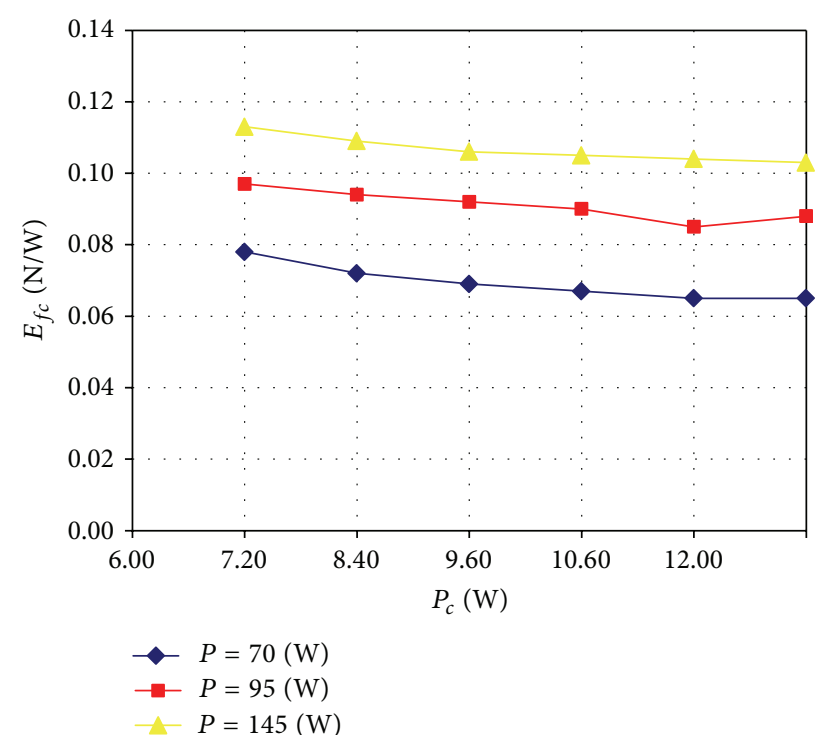

FIGURE 13: Variation of the tail boom efficiency $E_{f_{c}}$ according to the lateral force $F$ and the required power $P_{c}$ throughout the three functioning stages of the main rotor at a pitch angle $p=4^{\circ}$.

to lead to the same initial conclusion related to the formation of the family of linear functions $g_{N}^{\prime}$.

For $P=95[\mathrm{~W}]$ with constant $p=8^{0}$ and $\delta=2 \mathrm{~mm}$, we obtain the linear function $g_{N}^{\prime}$ which helps in determining the lateral force $F$ due to the Coandă effect:

$$
g_{N}^{\prime} \approx \frac{1}{100}(8,33 X+11) \text {. }
$$

The first conclusion is the increase of the value of lateral force $F$ due to a greater mass of air being entrained and used in the Coandă flow, which is achieved through modifying the pitch angle of the main rotor.

Power $P_{c}$ of the tail boom fan is the index variable $X$.

We determine the efficiency $E_{f}$ of a propelling device as the ratio of the propeller's generated force to the power required by it, $E_{f}=F / P_{0}$, in our case $F$ being the lateral force generated by the Coandă effect and $P_{o}$ the power consumed by the tail boom fan $P_{c}$.

We can therefore say that, in our case, index $E_{f_{c}}$ may be the efficiency of the tail boom (Figures 13 and 14).

\section{Conclusions}

The values of the geometrical and input parameters were respected and the experimental results were close to the computer-simulated ones.

Practically, in order to obtain a convenient force generated by the Coandă effect, a force which can be easily modified, some directional adjustable elements need to be placed on the length of the slots.

The force detected on the profile in each area of the Coandă flow is the difference between two distinct forces: one on the upper side and one on the lower side, of different strengths, the same direction and opposing directions, which

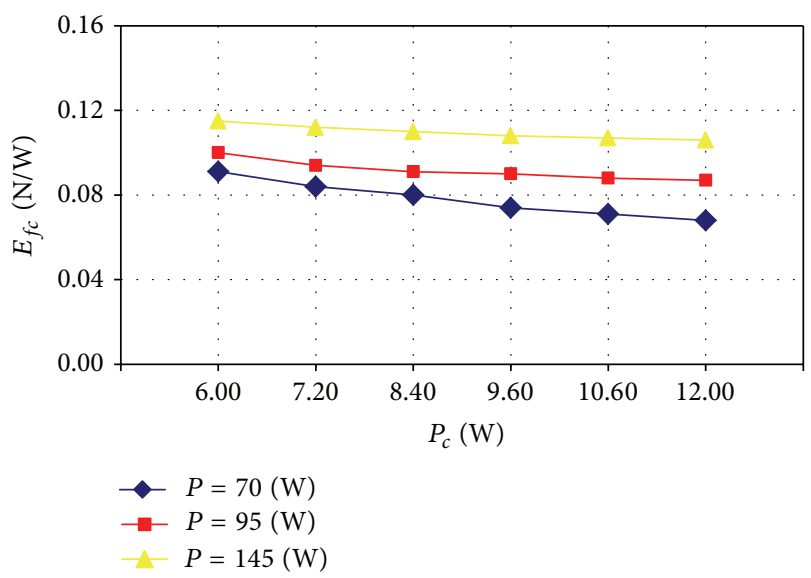

FigURE 14: Variation of the tail boom efficiency $E_{f_{c}}$ according to the lateral force $F$ and the required power $P_{c}$ throughout the three functioning stages of the main rotor at a pitch angle $p=8^{\circ}$.

are significantly affected by the geometry of the chosen profile.

The computational simulation of the tail geometry based on the optimal use of the two longitudinal Coandă slots facilitates the achievement of a Coandă flow, controllable via the speed of induced jet and the flow resulted from the main rotor of the helicopter. The result is a lateral force in accordance with the functioning requirements of the singlerotor helicopter.

\section{Conflict of Interests}

The authors declare that there is no conflict of interests regarding the publication of this paper.

\section{References}

[1] H. Coandă, Air-Source du Progrès, 1961.

[2] H. Coandă, "Fluid propulsion system," [Patent]: US3337121, 1967.

[3] C. Berbente, S. Dănăilă, and S. Berbente, "Analytic solutions for axisymmetric incompressible flows with wall injection and regression," Proceedings of the Romanian Academy, vol. 12, no. 3, pp. 221-229, 2011.

[4] I. Cîrciu, S. Dinea, and M. Boșcoianu, "Review of contributions regarding Coanda effect," Review of the Air Force Academy, vol. 2, no. 5, 2009.

[5] C. Rotaru, "Nonlinear characteristics of helicopter rotor blade airfoils: an analytical evaluation," Mathematical Problems in Engineering, vol. 2013, Article ID 503858, 9 pages, 2013.

[6] H. Zhang, Y. Li, and S. Deng, "A novel emergent state control law for an integrated helicopter/turboshaft engine system," Mathematical Problems in Engineering, vol. 2014, Article ID 385807, 14 pages, 2014.

[7] C. Berbente and S. Dinea, "On Kármán model for Coanda ejector with incompressible flow," University Politehnica of Bucharest Scientific Bulletin, vol. 71, no. 2, p. 19, 2009.

[8] H. Djojodihardjo, M. F. A. Hamid, A. A. Jaafar et al., "Computational study on the aerodynamic performance of wind turbine 
airfoil fitted with coandă jet," Journal of Renewable Energy, vol. 2013, Article ID 839319, 17 pages, 2013.

[9] D. L. Motoc, S. F. Bou, and R. B. Gimeno, "Effects of fibre orientation and content on the mechanical, dynamic mechanical and thermal expansion properties of multi-layered glass/carbon fibre-reinforced polymer composites," Journal of Composite Materials, 2014.

[10] D. L. Motoc and I. Curtu, "Dynamic mechanical analysis of multiphase polymeric composite materials," Materiale Plastice, vol. 46, no. 4, pp. 462-466, 2009.

[11] P. Ahmadi, M. Golestani, S. Nasrollahi, and A. R. Vali, "Combination of two nonlinear techniques applied to a 3-DOF helicopter," ISRN Aerospace Engineering, vol. 2014, Article ID 436072, 8 pages, 2014. 

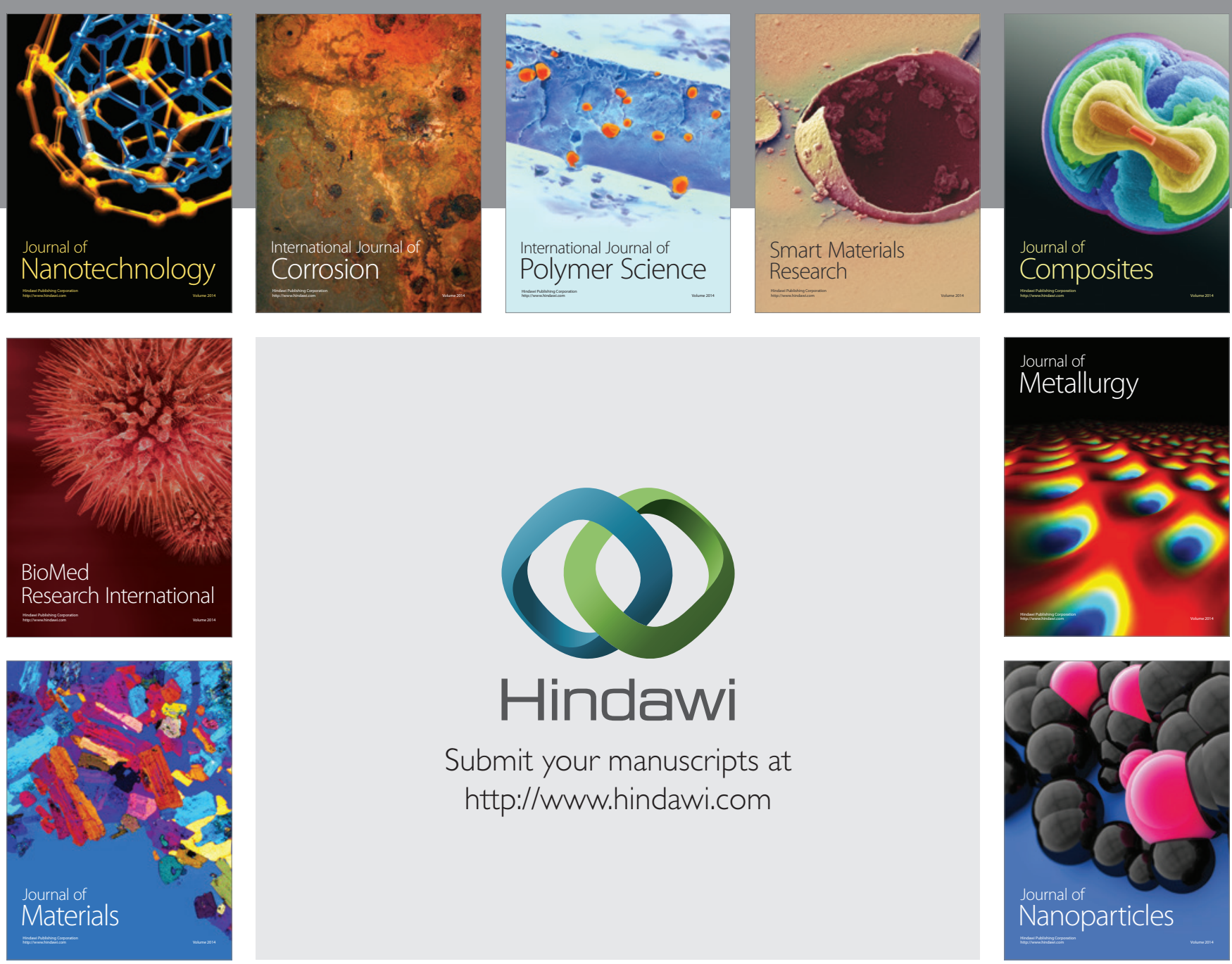

Submit your manuscripts at http://www.hindawi.com
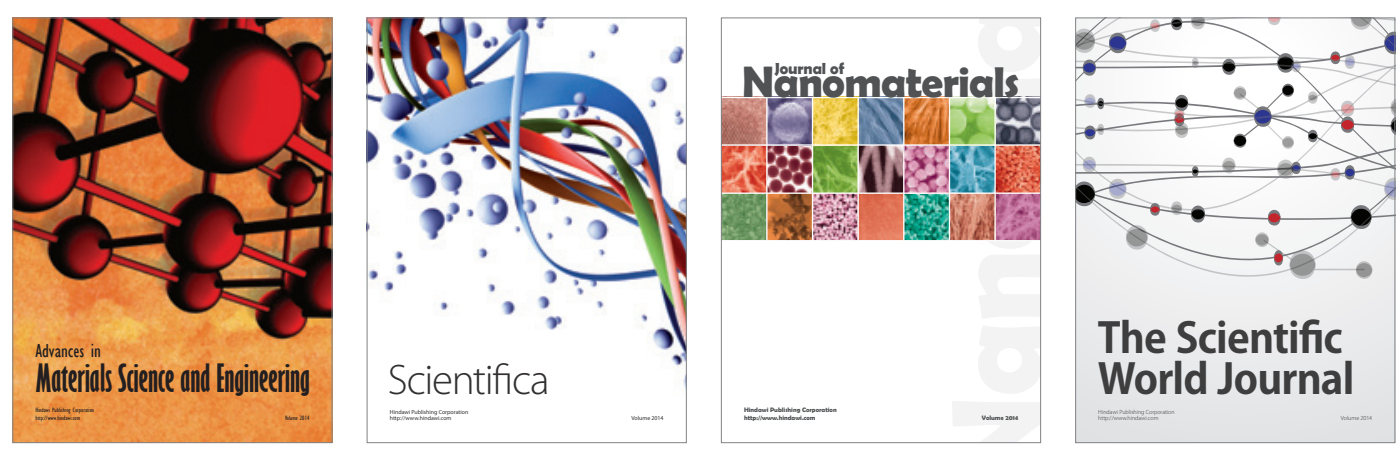

\section{The Scientific World Journal}
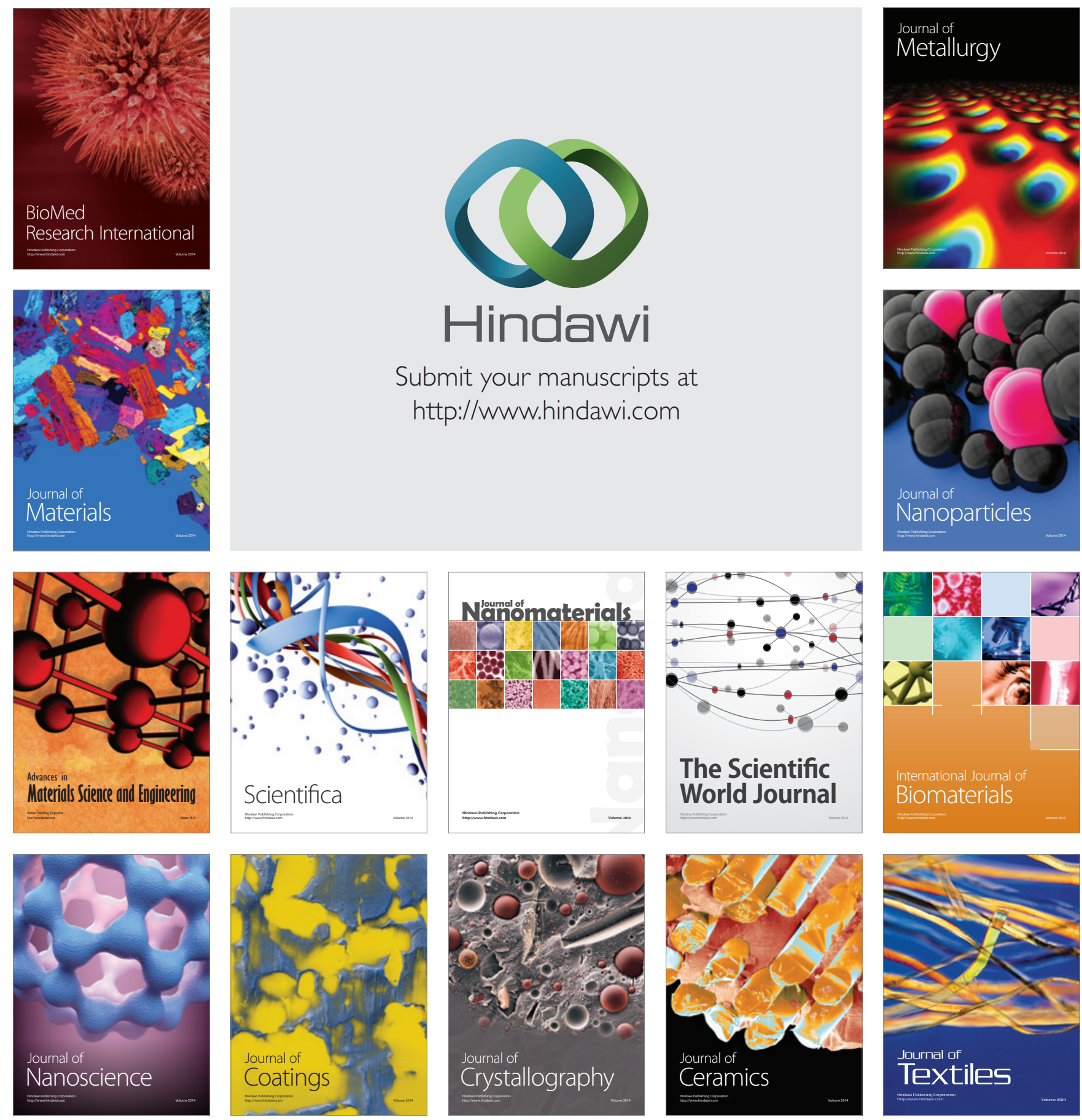